\title{
Organofluorine Compounds in Fluorine-18 Positron Emission Tomography Imaging
}

\author{
Ivor Smajlagic, Rozhin Rowshanpour, Lea Milkin and Travis Dudding* \\ Department of Chemistry, Brock University, Canada \\ *Corresponding author: Travis Dudding, Department of Chemistry, Brock University, St. Catharines, ON L2S 3A1, Canada, \\ Email: tdudding@brocku.ca
}

\begin{abstract}
The application of organofluorine compounds is widespread with many current uses in the life sciences and medical field. As modern methods for the introduction of fluorine into molecules continue to develop, so is the growing use of fluorine and its radioisotope, fluorine-18, in the medical field. This mini review summarizes some of the major advancements pertaining to ${ }^{18} \mathrm{~F}$ radiotracers for positron emission tomography (PET) imaging and its application as a tool to aid in the diagnosis of Alzheimer's disease and cancer. Further offered is a brief overview of synthetic methods for preparing organofluorine compounds and rise of organotrifluoroborates in ${ }^{18} \mathrm{~F}$ PET imaging.
\end{abstract}

Keywords: PET imaging; Fluorine; Radionuclide; Alzheimer's disease; Cancer; Organotrifluoroborates

\section{Introduction}

Organofluorine compounds are abundant in medicine and society-largely by human design and chemical synthesis, not de novo in Nature. In fact, only twenty-one fluorine-containing metabolites among an estimated 130,000 structurally characterized natural products are known [1-3]. This is in sharp contrast to $30 \%$ of agrochemicals and $20 \%$ of pharmaceuticals containing fluorine, including several of the top drugs, e.g., 5-fluorouracil, fluoxetine (Prozac), paroxetine (Paxil), ciprofloxacin (Cipro), mefloquine, and fluconazole [4]. Today, thanks to advancements in chemical synthesis, the incorporation of fluorine into compounds is becoming a simpler task that is enabling innovations in medicine and bio-oriented applications. With this has been major advancements, such as the ever-useful non-invasive positron emission tomography (PET) imaging technique [5,6]. In this regard, the use of unnatural radionuclide fluorine-18 $\left({ }^{18} \mathrm{~F}\right)$, with a fleeting half-life of $109.8 \mathrm{~min} / \mathrm{h}$, has a prominent status in ${ }^{18} \mathrm{~F}$ PET imaging [7-11]. Contributing to this widespread use is the small size (van der Waals radius of $1.47 \AA$ ) and high Pauling electronegativity of 3.98 of the fluorine atom, referred to by some as a "small atom with a big ego." What is more, fluorine has the ability to influence molecular conformation and improve metabolic stability, solubility, permeability, and protein binding $[12,13]$. Meanwhile, ${ }^{18} \mathrm{~F}$ is among one of the safest radioisotope probes owing to minimal radiation exposure upon administration, low-toxicity, and high signal-tonoise ratios [14].

In this short review, we touch upon the synthesis of fluorine-18 labeled organofluorine compounds and discuss select usages in ${ }^{18} \mathrm{~F}$ PET imaging for two widespread diseases, namely cancer and Alzheimer's disease. Additionally, we delve into timely developments surrounding the utility of organotrifluoroborate compounds and their promise in ${ }^{18} \mathrm{~F}$ PET imaging by highlighting a few examples. While by no means comprehensive, we hope this mini review provides a helpful resource for understanding the role of organofluorine compounds in ${ }^{18} \mathrm{~F}$ PET imaging, thus, bridging the health science and chemistry fields.

\section{Brief Overview of Methods for ${ }^{18} \mathrm{~F}$ incorporation}

One longstanding obstacle to ${ }^{18} \mathrm{~F}$ PET imaging remains synthetic methods for rapid incorporation of ${ }^{18} \mathrm{~F}$ into bio-relevant moleculesstemming from the short half-life of this radionuclide. In this context, classic preparative methods (syntheses) for incorporating fluorine into molecules include the use of fluorine gas, hydrogen fluoride, alkali-metal halides and/or the Balz-Schiemann reaction, which require harsh conditions making them unsuitable or 
challenging to implement [15]. Alternatively, nucleophilic aromatic substitution $\left(\mathrm{S}_{\mathrm{N}} \mathrm{Ar}\right)$ is a more viable means for preparing various ${ }^{18} \mathrm{~F}$ aryl-containing, metabolically-stable organofluorine compound radiotracers, e.g., $\left[{ }^{18} \mathrm{~F}\right]$ altanserin, $\left[{ }^{18} \mathrm{~F}\right]$ haloperidol and $\left[{ }^{18} \mathrm{~F}\right]$ flumazenil; however, $\mathrm{S}_{\mathrm{N}} \mathrm{Ar}$ reactions are often plagued by excessive heating and moderate reaction times (e.g., $>100^{\circ} \mathrm{C}$ for a period of 30 minutes) [16-18]. Although some of these strategies for late-stage ${ }^{18} \mathrm{~F}$ incorporation into molecules are not ideal, recent technologies are enabling this reactivity to occur under more mild conditions and fast reaction times, e.g., microwave heating as opposed to conventional heating. Complementing this alternative form of heating is the growing use of diaryliodonium salts, dediazoniation reactions, electrochemical radiofluorination and exploitation of nonhazardous electrophilic fluorine sources, e.g., $\left[{ }^{18} \mathrm{~F}\right]$ Selectfluor [19].

\section{Alzheimer's Disease and ${ }^{18}$ F PET Imaging}

${ }^{18} \mathrm{~F}$ PET imaging has proven its merit as a diagnostic tool, with its use in helping diagnose two pervasive illnesses, namely Alzheimer's disease and cancer, thus, making them exemplar cases for discussion. Turning first to Alzheimer's disease, this neurodegenerative disorder affects approximately $6 \%$ of the global population over the age of 65 and accounts for around $80 \%$ of all dementia diagnoses, with an associated cost for treatment in excess of $\$ 500$ billion annually [20-22]. Alzheimer's disease is characterized by a combination of neuropathological features, including extracellular brain amyloidosis, intracellular tau accumulation, brain atrophy and cell depletion [23]. As this is a progressive disorder, early-stage identification is of the utmost importance. To date, the majority of PET imaging approaches have targeted amyloid- $\beta$ aggregates due to its indisputable specific association with Alzheimer's disease [24]. In this context, ${ }^{18} \mathrm{~F}$-labeled amyloid radiotracers- $\left[{ }^{18} \mathrm{~F}\right]$ florbetaben , $\left[18^{\mathrm{F}}\right]$ flutemetamol and $\left[{ }^{18} \mathrm{~F}\right]$ florbetapir-have been implemented into clinical practice with promising outcomes. Although these radiotracers have shown remarkable accuracy in amyloid- $\beta$ detection to assist in diagnosis, they exhibit additional white matter binding, thus, decreasing specificity to amyloid- $\beta[25,26]$. While the frontiers of science are clearly being pushed forward with respect to the development of ${ }^{18} \mathrm{~F}$ radiotracers, this is still an imperfect process; there is an obvious need to implement more efficient ${ }^{18} \mathrm{~F}$ radiotracers that manifest in more specific binding to amyloid- $\beta$.

\section{Cancer and ${ }^{18} \mathrm{~F}$ PET Imaging}

Cancer, as the second leading cause of deaths worldwide, has a major impact on society as attested for by an estimated 9.6 million deaths in 2018. Globally, 1 in 6 deaths results from cancer, and by 2030 the number of new cancer cases per year is expected to rise to 23.6 million. This abnormal, uncontrollable cell growth and proliferation, otherwise known as cancer, has over 227 subtypes. In men, the highest percentages of cancer types occur in the prostate, lung and bronchus, colon and rectum, and urinary bladder, while in women cancer prevalence is highest in the breast, lung and bronchus, colon and rectum, uterine corpus, and thyroid. In contrast, children are most susceptible to cancers that target blood, the brain or lymph nodes [27]. Some conventional methods for monitoring prognosis and treatment of cancer include radiography, ultrasound, computed tomography (CT) and magnetic resonance imaging (MRI) [28]. More recently, $\left[{ }^{18} \mathrm{~F}\right]$ fluorodeoxyglucose -positron emission tomography $\left({ }^{18} \mathrm{~F}-\mathrm{DG}\right.$ PET) has emerged as an effective tool for characterizing tumors based on biochemical changes at the molecular level [29]. What is more, its use continues to grow with the number of ${ }^{18} \mathrm{~F}$-DG PET scans performed in the United States alone having increased nearly 9-fold in 2010. Although ${ }^{18} \mathrm{~F}-\mathrm{DG}$ is the most commonly employed radiotracer for PET imaging (96\% of PET studies in 2011 used ${ }^{18} \mathrm{~F}-\mathrm{DG}$ ), it has limitations in assessing several relevant tumors, such as prostate cancer [30]. Moreover, ${ }^{18} \mathrm{~F}$-DG PET scans are limited to simple metrics like maximum standardized uptake value, metabolic tumor volume, or total lesion glycolysis, which have limited predictive value. Therefore, there is a pressing need for the development and clinical application of different PET radiopharmaceuticals [31,32]. To meet this need, several newer agents have been studied in humans, including radiotracers classified by the metabolic processes they target, e.g., $\left({ }^{18} \mathrm{~F}-\mathrm{FLT}\right)$, hypoxia $\left({ }^{18} \mathrm{~F}-\mathrm{FMISO}\right)$, apoptosis $\left({ }^{18} \mathrm{~F}-\mathrm{ML}-10\right)$, protein synthesis $\left({ }^{18} \mathrm{~F}-\mathrm{FET}\right)$, membrane metabolism $\left({ }^{11} \mathrm{C}\right.$ choline), and tumor-specific agents $\left({ }^{18} \mathrm{~F}-\mathrm{FES}\right)[29]$.

\section{${ }^{18} \mathrm{~F}$ Labeled Organotrifluoroborates}

One significant breakthrough in ${ }^{18} \mathrm{~F}$ PET imaging has been the advancement of ${ }^{18} \mathrm{~F}$ labeled organotrifluoroborate imaging agents (e.g., ${ }^{18} \mathrm{~F}$ containing aryl trifluoroborates) [33,34]. Critical to the use of organotrifluoroborates as imaging agents, however, is chemical stability to hydrolytic defluorination resulting in free fluoride producing unwanted background signals making ${ }^{18} \mathrm{~F}$ detection difficult. Towards improving the stability of organotrifluoroborates, several strategies have emerged over the years. For example, Perrin et al. have developed electron-deficient aryl trifluoroborates $\left(\mathrm{ArBF}_{3}\right)$ having reduced hydrolytic defluorination rates as attested for by the half-lives $\left(t_{1 / 2}\right)$ of $43 \pm 4$ min vs. $2 \pm 0.04 \mathrm{~min}$ for 2,6-difluorophenyltrifluoroborate and phenyl trifluoroborate under identical conditions [35]. In extending $\mathrm{ArBF}_{3}$ stability further, onium ion stabilized trifluoroborates have been reported, wherein ammonium trifluoroborates were proven effective as in vivo imaging agents [36,37]. As a recent entry, we have reported stability studies and the synthesis of bis(amino)cyclopropenium trifluoroborate $\left(\mathrm{BAC}-\mathrm{BF}_{3}\right.$ ) adducts having remarkable stabilities toward hydrolysis, and presumable high lipophilic character, making them attractive targets for future ${ }^{18} \mathrm{~F}$ PET imaging applications (Figure 1) [38]. Taken together, these promising qualities provide a strong impetus for the development of new synthetic methods tailored to the design of ${ }^{18} \mathrm{~F}$ radiolabeled organotrifluoroborate molecules for ${ }^{18} \mathrm{~F}$ PET imaging and ongoing research in our group is exploring this aspect. 


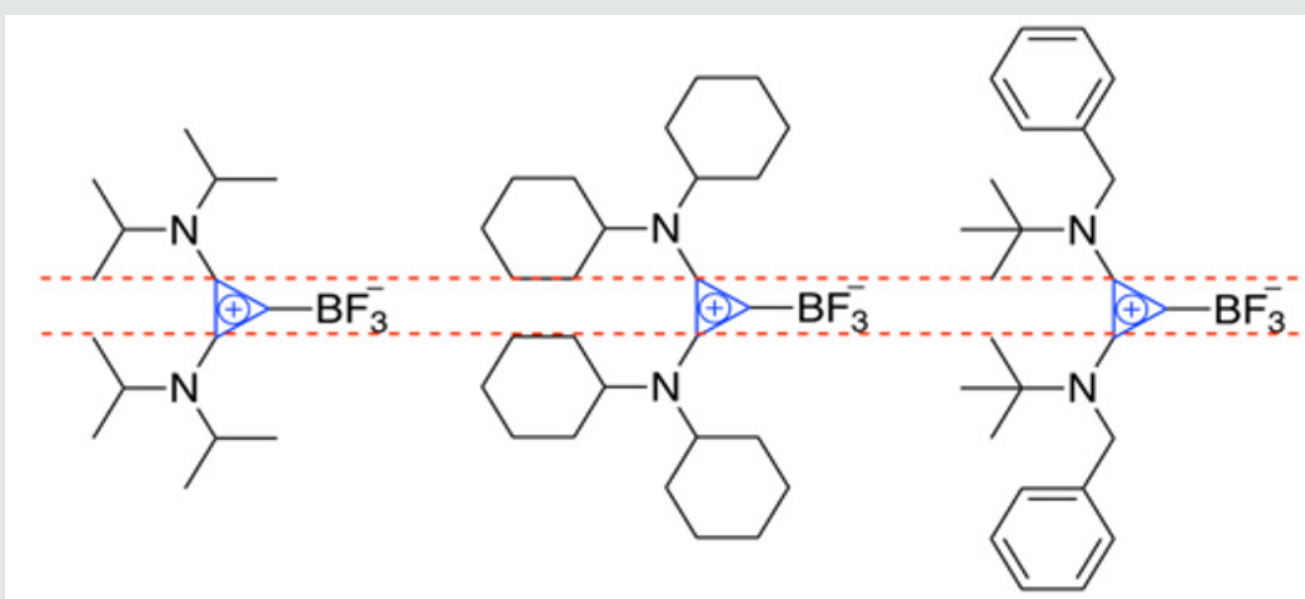

Variable substituents

Figure 1: A series of $\mathrm{BAC}-\mathrm{BF}_{3}$ compounds reported by Dudding and co-workers with variable substituents bound to the core cyclopropenium ring [38].

\section{Conclusion}

In this mini review, coverage of critical aspects relating to the synthesis of organofluorine compounds and application of the ${ }^{18} \mathrm{~F}$ isotope in PET imaging for Alzheimer's disease and cancer was provided. Furthermore, organotrifluoroborates were also highlighted as promising molecules in the context of ${ }^{18} \mathrm{~F}$ labeling that have seen particular growth in recent years. It is our hope this mini review, and the literature citations herein, will influence the future design of organofluorine radiotracers for improving current issues in the medical field.

\section{Acknowledgements}

T.D. acknowledges financial support from the Natural Science and Engineering Research Council (NSERC) Discovery grant (201904205) and Brock University.

\section{Funding}

\section{ORCID}

Travis Dudding: 0000-0002-2239-0818

\section{References}

1. Rosén J, Gottfries J, Muresan S, Backlund A, Oprea TI (2009) Novel chemical space exploration via natural products. J Med Chem 52(7): 1953-1962.

2. Gribble GW (1996) Progress in the Chemistry of Organic Natural Products 68: 1-498.

3. Gribble GW (2009) Progress in the Chemistry of Organic Natural Products 91: 1-613.

4. Furuya T, Kamlet AS, Ritter T (2011) Catalysis for fluorination and trifluromethylation. Nature 473(7348): 470-477.

5. Gillis EP, Eastman KJ, Hill MD, Donnelly DJ, Meanwell NA (2015) Applications of fluorine in medicinal chemistry. J Med Chem 58(21): 8315-8359.

6. Matthews PM, Rabiner EA, Passchier J, Gunn RN (2012) Positron emission tomography molecular imaging for drug development. Br J Clin Pharmacol 73(2): 175-186.

7. Müller K, Faeh C, Diederich F (2007) Fluorine in pharmaceuticals: looking beyond intuition. Science 317(5846): 1881-1886.

8. Purser S, Moore PR, Swallow S, Gouverneur V (2008) Fluorine in medicinal chemistry. Chem Soc Rev 37(2): 320-330.

9. Jeschke P (2004) The unique role of fluorine in the design of active ingredients for modern crop production. ChemBioChem 5(5): 570-589.

10. Hung M, Farnham W, Feiring A, Rozen S (1999) Fluoropolymers: Synthesis 1:51-66.

11. Ametamey SM, Honer M, Schubiger PA (2008) Molecular imaging with PET. Chem Rev 108(5): 1501-1516.

12. Gillis EP, Eastman KJ, Hill MD, Donnelly DJ, Meanwell NA (2015) Applications of fluorine in medicinal chemistry. J Med Chem 58(21): 8315-8359.

13. Böhm HJ, Banner D, Bendels S, Kansy M, Kuhn B (2004) Fluorine in medicinal chemistry. ChemBioChem 5(5): 637-643.

14. Kilbourn MR, Huizenga JR (1990) Fluorine-18 labeling of radiopharmaceuticals.

15. Neumann CN, Ritter T (2015) Late stage fluorination: fancy novelty or useful tool? Angew Chem Int Ed 54(11): 3216-3221.

16. Lemaire C, Cantineau R, Guillaume M, Plenevaux A, Christiaens L (1991) Fluorine-16- Altanserin: a radioligand for the study of serotonin receptors with PET: radiolabeling and in vivo biologic behaviour in rats. J Nucl Med 32(12): 2266-2272.

17. Kilbourn MR, Welch MJ, Dence CS, Tewson TJ, Saji H (1984) Carrieradded and no-carrier-added synthesis of $\left[{ }^{18} \mathrm{~F}\right]$ spiroperidol and $\left[{ }^{18} \mathrm{~F}\right]$ haloperidol. Int J Appl Radiat Isot 35(7): 591- 598.

18. Massaweh G, Schirrmacher E, la Fougere C, Kovacevic M, Wängler C, et al. (2009) Improved work-up procedure for the first production of [18 F] flumazenil and first results of its use with a high-resolution research tomograph in human stroke. Nucl Med Biol 36(7): 721-727.

19. Tredwell M, Gouverneur V (2012) ${ }^{18} \mathrm{~F}$ Labeling of Arenes. Angew Chem Int Ed 51(46): 11426-11437.

20. Crous-Bou M, Minguillón C, Gramunt N, Monlinuevo JL (2017) Alzheimer's disease prevention: from risk factors to early intervention. Alzheimers Res Ther 9(71): 1-9. 
21. Ferri CP, Prince M, Brayne C, Brodaty H, Fratiglioni L (2005) Global prevalence of dementia: a Delphi consensus study. Lancet 366(9503): 2112-2117

22. Takizawa C, Thompson PL, van Walsem A, Faure C, Maier WC (2015) Epidemiological and economic burden of Alzheimer's disease: a systematic literature review of data across Europe and the United States of America. J Alzheimers Dis 43(4): 1271-1284.

23. Duyckaerts C, Delatour B, Potier MC (2009) Classification and basic pathology of Alzheimer disease. Acta Neuropathol 118(1): 5-36.

24. Schilling LP, Zimmer ER, Shin M, Leuzy A, Pascoal TA (2016) Imaging Alzheimer's disease pathophysiology with PET. Dement Neuropsychol 10(2): 79-90.

25. Yeo JM, Waddell B, Khan Z, Suvankar P (2015) A systematic review and meta-analysis of ${ }^{18} \mathrm{~F}$-labeled amyloid imaging in Alzheimer's disease. Alzheimers Dement (Amst) 1(1): 5-13.

26. Sabri O, Seibyl J, Rowe C, Barthel H (2015) Beta-amyloid imaging with florbetaben. Clin Transl Imaging 3(1): 13-26.

27. Siegel RL, Miller KD, Jemal A (2016) Cancer statistics, 2016. CA Cancer J Clin 66(1): 7-30.

28. Patel AA, Patel BM, Patel KM (2013) Role of PET scan in clinical practice. GMJ 68(2):19-22

29. Farwell MD, Pryma DA, Mankoff DA (2014) PET/CT imaging in cancer: current applications and future directions. Cancer 120(22): 3433-3445.

30. Hassanpour SH, Dehghani M (2017) Review of cancer from perspective of molecular. J Cancer Res Pract 4(4): 127-129.
31. Giammarile F, Castelluci P, Dierckx R, Lobato EE, Farsad M (2019) NonFDG PET/CT in diagnostic oncology: a pictorial review. Eur J Hybrid Imaging 3(20): 1-46.

32. Beichel RR, Ulrich EJ, Smith BJ, Bauer C, Brown B, et al. (2019) FDG PET based prediction of response in head and neck cancer treatment: assessment of new quantitative imaging features. PLoS One 14(4): 1-13.

33. Li Y, Guo J, Tang S, Lang L, Chen X, et al. (2013) One-step and one-pot-twostep radiosynthesis of cyclo- RGD- ${ }^{18} \mathrm{~F}$-aryltrifluoroborate conjugates for functional imaging. Am J Nucl Med Mol Imaging 3(1): 44-56.

34. Ting R, Harwig CW, auf dem Keller U, McCormick S, Austin P, et al. (2008) Toward $\left[{ }^{18} \mathrm{~F}\right]$ - labeled aryltrifluoroborate radiotracers: in vivo positron emission tomography imaging of stable aryltrifluoroborate clearance in mice. J Am Chem Soc 130(36): 12045-12055.

35. Ting R, Harwig CW, Lo J, Li Y, Adam MJ, et al. (2008) Substituent effects on aryltrifluoroborate solvolysis in water: implications for Suzuki-Miyaura coupling and the design of stable ${ }^{18} \mathrm{~F}$-labeled aryltrifluoroborates for use in PET imaging. J Org Chem 73(12): 4662-4670.

36. Li Z, Chansaenpak K, Liu S, Wade CR, Conti PS, et al. (2012) Harvesting ${ }^{18} \mathrm{~F}$-fluoride ions in water via direct ${ }^{18} \mathrm{~F}-{ }^{19} \mathrm{~F}$ isotopic exchange: radiofluorination of zwitterionic aryltrifluoroborates and in vivo stability studies. Med Chem Comm 3(10): 1305-1308.

37. Liu Z, Pourghiasian M, Radtke MA, Lau J, Pan J, et al. (2014) An organotrifluoroborate for broadly applicable one- step ${ }^{18} \mathrm{~F}$ - labeling. Angew Chem Int Ed 53(44): 11876-11880.

38. Mir R, Dudding T (2018) Bis(amino)cyclopropenium trifluoroborates: synthesis, hydrolytic stability studies, and DFT insights. J Org Chem

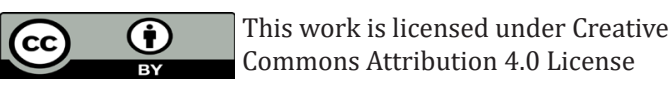

To Submit Your Article Click Here:

Submit Article

DOI: 10.32474/RRHOAJ.2020.05.000213

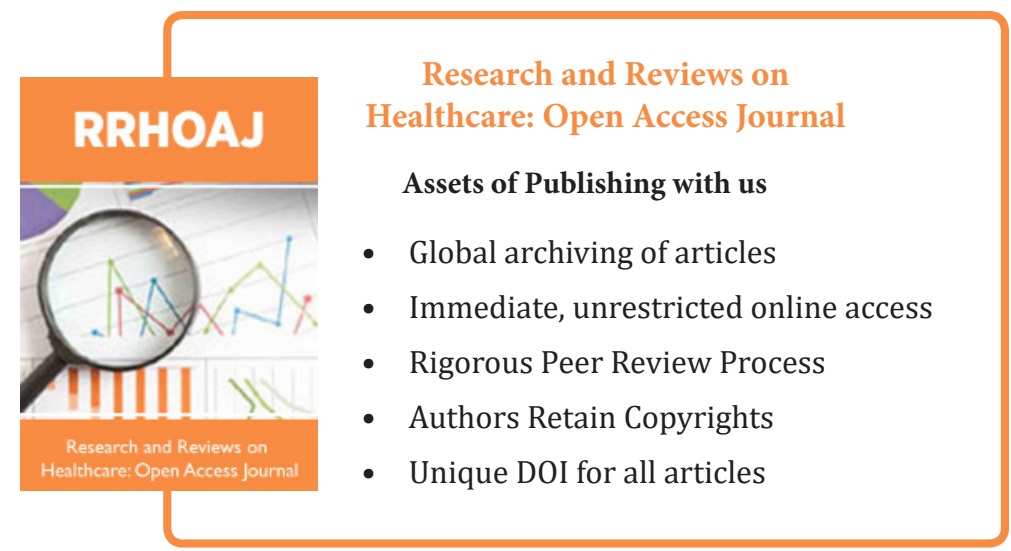

